\title{
FONTES, FORMAS DE APLICAÇÃO E DOSES DE NITROGÊNIO EM FEIJOEIRO IRRIGADO SOB PLANTIO DIRETO ${ }^{1}$
}

\author{
Paulo César Ribeiro da Cunha², Pedro Marques da Silveira ${ }^{3}$, \\ Paulo Alcanfor Ximenes ${ }^{4}$, Roberta de Freitas Souza ${ }^{4}$, José Alves Júnior ${ }^{4}$, Jorge Luiz do Nascimento ${ }^{4}$
}

\begin{abstract}
NITROGEN SOURCES, FORMS OF APPLICATION AND DOSES IN IRRIGATED COMMON BEAN UNDER NO-TILLAGE SYSTEM

The loss of nitrogen by ammonia volatilization is the main factor responsible for the low utilization of urea, especially when applied to the soil surface. This experiment evaluated the efficiency of urea containing $0,045 \%$ of NBPT (n-butyl thiophosphoric triamide) addictive, when compared with regular urea, and the effects of rates and forms of application of covering nitrogen over irrigated common bean component parts and yield, cultivated under no-tillage system, on a Distrudox soil, managed for three consecutive years under crop-livestock integrated system. A randomized complete blocks design was used, in a $2 \times 2 \times 4$ factorial scheme, consisting of two nitrogen sources (common and additivated urea), two application methods (surface and incorporated), and four $\mathrm{N}$ doses $\left(0 \mathrm{~kg} \mathrm{ha}^{-1}, 60 \mathrm{~kg} \mathrm{ha}^{-1}, 120 \mathrm{~kg} \mathrm{ha}^{-1}\right.$, and $180 \mathrm{~kg} \mathrm{ha}^{-1}$ ), with four replications. When compared to the common urea, additivated urea did not provide significant increases in yield. The additivated source resulted in higher plants and it was noticed a higher yield rate, when the fertilizer was used.
\end{abstract}

KEY-WORDS: Phaseolus vulgaris L.; crop-livestock integrated system; yield.

\section{INTRODUÇÃO}

A produção de feijão de inverno, cultivado em plantio direto, sob integração lavoura-pecuária, é recente e tem crescido nos últimos anos. Dentre as tecnologias indicadas para este sistema de cultivo, a adubação nitrogenada é abordada com maior número de questionamentos, pois, neste sistema, o $\mathrm{N}$ é aplicado em cobertura sobre os resíduos culturais, o que influencia na dinâmica do nutriente (Kluthcouski \& Stone 2003).

Dentre as fontes de N, a ureia é o fertilizante nitrogenado sólido mais utilizado no mundo, por

\section{RESUMO}

A perda de nitrogênio por volatilização de amônia constitui o principal fator responsável pelo baixo aproveitamento da ureia, principalmente quando aplicada sobre a superfície do solo. Objetivou-se, com este trabalho, avaliar a eficiência de ureia contendo $0,045 \%$ de aditivo NBPT (n-butil tiofosfórico triamida), em comparação com ureia normal, e os efeitos de doses e formas de aplicação de nitrogênio fornecido em cobertura, sobre os componentes e a produtividade de feijoeiro irrigado, cultivado em plantio direto. O solo da área experimental foi classificado como Latossolo Vermelho distroférrico típico, sendo manejado por três anos consecutivos sob integração lavourapecuária. $\mathrm{O}$ delineamento experimental foi o de blocos completos casualizados, em esquema fatorial $2 \times 2 \times 4$, constituído pela combinação de duas fontes de $\mathrm{N}$ (ureia comum e aditivada), duas formas de aplicação (superficial e incorporada) e quatro doses de $\mathrm{N}\left(0 \mathrm{~kg} \mathrm{ha}^{-1}, 60 \mathrm{~kg} \mathrm{ha}^{-1}, 120 \mathrm{~kg} \mathrm{ha}^{-1}\right.$ e $\left.180 \mathrm{~kg} \mathrm{ha}^{-1}\right)$, com quatro repetições. Em comparação com a ureia comum, a ureia aditivada não propiciou aumentos significativos na produtividade. Com a fonte contendo aditivo, foram obtidas plantas mais altas e obtevese maior produtividade, com a incorporação do fertilizante.

PALAVRAS-CHAVE: Phaseolus vulgaris L.; integração lavourapecuária; produtividade.

apresentar elevado conteúdo de $\mathrm{N}$ e menor custo por unidade do nutriente aplicado ao solo. A despeito destes aspectos favoráveis, a ureia apresenta, como característica indesejável, reação inicial alcalina no solo, tornando-o suscetível a perdas de nitrogênio por volatilização de amônia, especialmente quando aplicada à superfície dos solos cobertos com resíduos de plantas, sendo a incorporação do fertilizante uma forma de se reduzir as perdas (Sangoi et al. 2003). A incorporação da ureia ao solo é uma alternativa para se reter maior quantidade de amônio no solo e minimizar as perdas de amônia por volatilização (Lara Cabezas et al. 2000), por aumentar o

1. Trabalho recebido em set./2009 e aceito para publicação em jan./2011 ( ${ }^{\circ}$ registro: PAT 7515/ DOI 10.5216/pat.v41i1.7515).

2. Instituto Federal de Educação, Ciência e Tecnologia Goiano, Campus Urutaí, Urutaí, GO, Brasil.

E-mail: pcdacunha@hotmail.com.

3. Embrapa Arroz e Feijão, Santo Antônio de Goiás, GO, Brasil.E-mail: pmarques@cnpaf.embrapa.br.

4. Universidade Federal de Goiás, Escola de Agronomia e Engenharia de Alimentos, Goiânia, GO, Brasil.

E-mails: pauloalcanfor@gmail.com,robertadfs@yahoo.com.br, jose.junior@pesquisador.cnpq.br, jln@agro.ufg.br. 
contato entre o fertilizante e o solo, o que favorece a adsorção do $\mathrm{NH}_{4}^{+}$às cargas negativas do solo. Além disto, quando a ureia é incorporada e há liberação de $\mathrm{N}$ na forma de $\mathrm{NH}_{3}$, o caminho que o gás precisa percorrer até chegar à superfície é maior, reduzindo as perdas de $\mathrm{NH}_{3}$, devido à reação com o $\mathrm{H}^{+}$presente em solução, que resulta na formação de amônio $\left(\mathrm{NH}_{4}^{+}\right)$.

O feijoeiro é considerado uma planta exigente em nutrientes, em decorrência do sistema radicular superficial e ciclo curto, e, dentre os nutrientes, o nitrogênio é absorvido em quantidade mais elevada. Tem-se constatado a deficiência de $\mathrm{N}$, quando cultivado em sistema plantio direto (SPD), tornando necessária a utilização de maiores doses (Soratto et al. 2004), principalmente quando cultivado em sucessão a gramíneas (Silva \& Silveira 2000, Silveira et al. 2005, Gomes Júnior et al. 2008), pois o incremento do conteúdo de matéria orgânica verificado nas camadas superficiais do solo tende a aumentar a população microbiana e a CTC (Bayer \& Mielniczuk 1997). Com isto, tem-se maior atividade da uréase, que cataliza a hidrólise da ureia, favorecendo a vo-

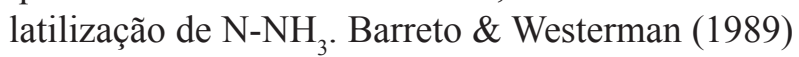
observaram que a atividade da uréase em resíduos culturais e em solos sob plantio direto é, respectivamente, trinta vezes e quatro vezes maior que em solos sob cultivo convencional.

Uma alternativa para se reduzirem as perdas de N em SPD é a utilização de fontes menos sujeitas a perdas por volatilização, para fornecer $\mathrm{N} \mathrm{em}$ cobertura (Costa et al. 2003), principalmente ao feijoeiro cultivado neste sistema, sobre resíduos de milho consorciado com braquiárias. Neste sentido, várias modificações têm sido feitas em fertilizantes contendo ureia, a fim de se reduzir perdas por volatilização e aumentar a eficiência de uso da ureia. Uma das possibilidades consiste no uso de inibidores de uréase, para reduzir a taxa ou velocidade de hidrólise da ureia e, assim, reduzir as perdas de $\mathrm{N}$ por volatilização. Watson (2000) revisou o assunto, destacando o aditivo NBPT (n-butil tiofosfórico triamida ou N-n-butiltriamida do ácido tiofosfórico) como, aparentemente, o mais promissor composto desenvolvido até o momento.

O NBPT é um composto que apresenta características de solubilidade e difusividade similares às da ureia (Watson 2000) e vem proporcionando a obtenção dos melhores resultados. O NBPT não é um inibidor direto da uréase. Ele tem que ser convertido ao seu análogo de oxigênio (fosfato de N-n-butiltriamida), denominado NBPTO, que é o verdadeiro inibidor.

O NBPT é capaz de inibir a degradação enzimática da ureia, por um período de até 14 dias (Watson 2000). Ao impedir a rápida hidrólise, o inibidor aumenta as chances de que chuvas ou irrigação incorporem a ureia ao solo. Em condições de solo úmido e altas temperaturas, picos de volatilização de $\mathrm{NH}_{3}$ ocorrem no segundo ou terceiro dia após aplicação (Cantarella et al. 2003). Em solo seco, foram observadas baixas perdas, até o quinto dia, sendo a eficiência do NBPT favorecida pela ocorrência de chuvas suficientes para incorporar a ureia ao solo, em intervalo de três a sete dias após a aplicação (Contin 2007). Scivittaro et al. (2008) observaram, com aplicação da ureia aditivada, que o intervalo de até dez dias sem irrigação não causa prejuízos à produtividade e à utilização do $\mathrm{N}$ pelo arroz.

O NBPT tem sido testado em alguns países, com resultados geralmente satisfatórios, sendo eficiente em baixas concentrações (Watson et al. 1994). Em condições de clima temperado, Malhi et al. (2001) observaram, em SPD, aumento da eficiência fertilizante tanto da ureia como do uran tratados com NBPT. Uma formulação comercial, contendo de $20 \%$ a 25\% de NBPT, patenteada com o nome "Agrotain", está disponível no mercado, para ser misturada com fertilizantes nitrogenados já fabricados. A formulação comercial em uso é empregada em concentrações que variam de $500 \mathrm{mg}$ a $1.000 \mathrm{mg}$ NBPT kg-1 ureia. No Brasil, a dose que vem sendo usada é de cerca de $530 \mathrm{mg} \mathrm{kg}^{-1}$.

Com a adoção de novos sistemas de produção e a preocupação crescente em desenvolver uma agricultura mais sustentável, o desafio do manejo de nitrogênio consiste em aumentar as quantidades absorvidas pelas culturas e diminuir as perdas do sistema solo-planta (Amado et al. 2000). No entanto, são praticamente inexistentes estudos acerca da influência da ureia aditivada com NBPT e da prática de incorporação do fertilizante sobre a produtividade do feijoeiro, em condições tropicais.

Neste contexto, objetivou-se, com este trabalho, avaliar a resposta do feijoeiro irrigado, cultivado em condições de plantio direto, sob integração lavoura-pecuária, à adubação com duas fontes de $\mathrm{N}$ (ureia normal e aditivada), duas formas de aplicação (em superfície e incorporada) e quatro doses de $\mathrm{N}$ em cobertura. 


\section{MATERIAL E MÉTODOS}

O experimento foi desenvolvido em 2007, em área irrigada por pivô central, com plantio direto na palha, manejada por três anos consecutivos sob integração lavoura-pecuária, na Fazenda Capivara, pertencente à Embrapa Arroz e Feijão, no município de Santo Antônio de Goiás, GO (16²8'S, 49¹7'W e $823 \mathrm{~m}$ de altitude).

O solo do local é classificado como Latossolo Vermelho distroférrico típico e suas características químicas, na camada $0,00-0,20 \mathrm{~m}$, foram determinadas antes da instalação do experimento, tendo apresentado os seguintes resultados: $\mathrm{pH}\left(\mathrm{H}_{2} \mathrm{O}\right)$ : 5,7; 20,5 $\mathrm{mmol}_{\mathrm{c}} \mathrm{dm}^{-3} \mathrm{de} \mathrm{Ca} ; 7,4 \mathrm{mmol}_{\mathrm{c}} \mathrm{dm}^{-3} \mathrm{de} \mathrm{Mg}^{2}$; $21,5 \mathrm{mg} \mathrm{dm}^{-3} \mathrm{de} \mathrm{P} ; 101 \mathrm{mg} \mathrm{dm}^{-3} \mathrm{de} \mathrm{K} ; 2,2 \mathrm{mg} \mathrm{dm}^{-3} \mathrm{de}$ $\mathrm{Cu} ; 8,1 \mathrm{mg} \mathrm{dm}^{-3} \mathrm{de} \mathrm{Zn;} 62 \mathrm{mg} \mathrm{dm}^{-3} \mathrm{de} \mathrm{Fe} ; 14 \mathrm{mg} \mathrm{dm}^{-3}$ de $\mathrm{Mn}$; e $19 \mathrm{~g} \mathrm{dm}^{-3}$ de MO. A análise granulométrica apresentou $490 \mathrm{~g} \mathrm{~kg}^{-1}, 270 \mathrm{~g} \mathrm{~kg}^{-1}$ e $240 \mathrm{~g} \mathrm{~kg}^{-1}$, respectivamente, de argila, silte e areia.

A área encontrava-se sob cobertura de Brachiaria ruziziensis e realizou-se a dessecação do material vegetal com aplicação do herbicida glyphosate (1.440 $\mathrm{g} \mathrm{ha}^{-1}$ do equivalente ácido). A semeadura do feijão, cultivar BRS Supremo, foi realizada mecanicamente, em 06/07/2007, com espaçamento de $0,45 \mathrm{~m}$ entre linhas e 15 sementes por metro. A adubação básica, nos sulcos de semeadura, foi de $380 \mathrm{~kg} \mathrm{ha}^{-1}$ da fórmula 04-30-10, realizada levando-se em consideração as características químicas do solo.

$\mathrm{O}$ delineamento experimental utilizado foi o de blocos ao acaso, em esquema fatorial $2 \times 2 \times 4$, com quatro repetições. Os tratamentos foram constituídos pela combinação de duas fontes de $\mathrm{N}$ (ureia normal e ureia contendo $0,045 \%$ de aditivo NBPT - n-butil tiofosfórico triamida), duas formas de aplicação (em superfície e incorporada) e quatro doses de $\mathrm{N}$ $\left(0 \mathrm{~kg} \mathrm{ha}^{-1}, 60 \mathrm{~kg} \mathrm{ha}^{-1}, 120 \mathrm{~kg} \mathrm{ha}^{-1}\right.$ e $\left.180 \mathrm{~kg} \mathrm{ha}^{-1}\right) \mathrm{em}$ cobertura. Cada parcela foi constituída por seis linhas de 5,0 $\mathrm{m}$ de comprimento. Aárea útil foi formada pelas quatro linhas centrais, desprezando-se meio metro em ambas as extremidades de cada linha, sendo que, em duas linhas, avaliou-se a produtividade e, em duas linhas, foram realizadas as amostragens de plantas.

As doses de N (ureia) foram parceladas em duas aplicações, efetuadas manualmente, sendo a primeira com plantas apresentando o terceiro trifólio totalmente expandido, estádio $\mathrm{V}_{(4-3)}$, e, a segunda, com a presença do sexto trifólio $\mathrm{V}_{(4-6)}$, ambas em solo úmido. Nos tratamentos sem incorporação, o fertilizante foi distribuído sobre a superfície do solo coberto com resíduos, distante, aproximadamente, 0,10 m das fileiras de plantas. Na mesma posição, nos tratamentos com incorporação, foram abertos, manualmente, utilizando-se enxadas, sulcos com, aproximadamente, $0,05 \mathrm{~m}$ de profundidade e o fertilizante foi distribuído e, posteriormente, coberto por solo e cobertura vegetal. Após as aplicações, não foram realizadas irrigações, por um período de 48 horas, durante as quais as médias das temperaturas máximas e mínimas, nos dois períodos, foram de $30,8^{\circ} \mathrm{C}$ e $15,6^{\circ} \mathrm{C}$; e $28,9^{\circ} \mathrm{C}$ e $14,8^{\circ} \mathrm{C}$, respectivamente, na primeira e segunda aplicação.

No início do experimento, foram instaladas três baterias, compostas por dois tensiômetros, posicionados na linha de semeadura, em duas profundidades $(0,15 \mathrm{~m}$ e $0,30 \mathrm{~m})$, lado a lado, dentro das parcelas. Adotou-se, como critério para irrigação, o momento em que a média das leituras dos aparelhos instalados a $0,15 \mathrm{~m}$ de profundidade acusaram tensões da água no solo entre $30 \mathrm{kPa}$ e $35 \mathrm{kPa}$ (Silveira \& Stone 1994). A lâmina de água aplicada foi estabelecida com base na curva característica de retenção de água do solo e aplicou-se a lâmina líquida de 10,96 mm, suficiente para elevar o solo à capacidade de campo, com tensão de $6 \mathrm{kPa}$.

O controle das plantas daninhas foi efetuado com aplicações sequenciais dos herbicidas fluazifop-p-butil e fomesafen $\left(187,5 \mathrm{~g} \mathrm{ha}^{-1}\right.$ do i.a. e $150 \mathrm{~g} \mathrm{ha}^{-1}$ do i.a.). Durante o desenvolvimento da cultura, foram realizados todos os tratos culturais e fitossanitários recomendados para a cultura do feijoeiro.

Por ocasião da colheita (estádio R9), foram coletadas dez plantas por parcela e determinados os seguintes componentes: altura de plantas (medida do nível do solo ao ápice da planta); número de vagens por planta; número de sementes por vagem; e massa de cem grãos. Em duas linhas centrais da área útil de cada parcela, fez-se avaliação do número de plantas e produtividade de grãos, sendo o teor de água dos grãos corrigido para $0,13 \mathrm{~kg} \mathrm{~kg}^{-1}$ (base úmida).

Os resultados foram submetidos a análise de variância e as médias referentes às fontes e formas de aplicação foram comparadas pelo teste Tukey, a $1 \%$ e $5 \%$, enquanto os efeitos das doses de $\mathrm{N}$ foram avaliados por meio da análise de regressão. Testou-se a significância dos componentes linear e quadrático, tendo-se escolhido o modelo com maior grau de significância, e foram realizadas análises de correlação simples entre as características agronômicas 
do feijoeiro. Determinou-se, também, o fator N, que é o fator de utilização do $\mathrm{N}$, mediante a relação do $\mathrm{N}$ aplicado $\left(\mathrm{kg} \mathrm{ha}^{-1}\right)$ e a produtividade incrementada $\left(\mathrm{kg} \mathrm{ha}^{-1}\right)$, em relação à testemunha (sem aplicação de N), com ambas as fontes e formas de aplicação.

\section{RESULTADOS E DISCUSSÃO}

Não houve efeito significativo das fontes de $\mathrm{N}$ sobre a produtividade de grãos, permitindo afirmar que, nas condições experimentais, a aplicação da ureia aditivada com $0,045 \%$ de aditivo NBPT não proporcionou incrementos na produtividade do feijoeiro e nos seus componentes. No entanto, com esta fonte, foram obtidas plantas mais altas (Tabela 1).

Com relação às formas de aplicação do $\mathrm{N}$, com ambas as fontes, maiores produtividades foram observadas quando o $\mathrm{N}$ foi incorporado ao solo (Tabela 1). Tal resultado, provavelmente, se deve ao fato de a incorporação da ureia reduzir as perdas por volatilização de amônia. Ceretta et al. (2002) e Sangoi et al. (2003) observaram que a incorporação ocasionou menor volatilização de amônia, além de menor imobilização microbiana, o que se deve ao menor contato do $\mathrm{N}$ com os resíduos vegetais presentes na superfície do solo.

A aplicação de $\mathrm{N}$ em cobertura, com ambas as fontes, propiciou aumento na produtividade do feijoeiro. As doses de $\mathrm{N}$ influenciaram $(\mathrm{p}<0,01)$ a produtividade de grãos, bem como os componentes da produtividade, com exceção do número de grãos por vagem (Tabela 1 ).

Os resultados obtidos neste trabalho evidenciam que há elevada demanda de $\mathrm{N}$ pelo feijoeiro, quando cultivado no sistema plantio direto, principalmente em sucessão a gramíneas, e condizem com o observado por Silveira et al. (2005) e por Gomes Júnior et al. (2008). Maior exigência de N, nestas

Tabela 1. Produtividade de grãos, vagens por planta, grãos por vagem, massa de cem grãos e altura de plantas, considerando-se fontes, formas de aplicação e doses de nitrogênio em plantio direto ${ }^{1}$ (Santo Antônio de Goiás, GO, 2007).

\begin{tabular}{|c|c|c|c|c|c|}
\hline Tratamentos & $\begin{array}{l}\text { Produtividade de grãos } \\
\qquad\left(\mathrm{kg} \mathrm{ha}^{-1}\right)\end{array}$ & $\begin{array}{l}\text { Número de vagens } \\
\text { por planta }\end{array}$ & $\begin{array}{l}\text { Número de grãos } \\
\text { por vagem }\end{array}$ & $\begin{array}{l}\text { Massa de cem grãos } \\
(\mathrm{g})\end{array}$ & $\begin{array}{l}\text { Altura da } \\
\text { planta }(\mathrm{cm})\end{array}$ \\
\hline \multicolumn{6}{|c|}{ Fontes $(\mathrm{F})$} \\
\hline Ureia normal & 2962 & 13,42 & 6,64 & 26,26 & $65,06 \mathrm{a}$ \\
\hline Ureia aditivada $^{2}$ & 3103 & 14,63 & 6,44 & 26,40 & $68,87 b$ \\
\hline Teste F & $3,86^{\mathrm{ns}}$ & $2,58^{\mathrm{ns}}$ & $1,68^{\mathrm{ns}}$ & $0,21^{\mathrm{ns}}$ & $8,95^{* *}$ \\
\hline DMS (5\%) & 145 & 1,53 & 0,31 & 0,62 & 2,58 \\
\hline CV $(\%)$ & 5,87 & 11,86 & 3,95 & 9,68 & 5,66 \\
\hline \multicolumn{6}{|c|}{ Formas de aplicação (Fa) } \\
\hline Superfície & $2874 a$ & 13,74 & 6,51 & 26,14 & 66,16 \\
\hline Incorporada & $3190 \mathrm{~b}$ & 14,31 & 6,57 & 26,53 & 67,77 \\
\hline Teste F & $19,58^{* *}$ & $0,56^{\mathrm{ns}}$ & $0,16^{\mathrm{ns}}$ & $1,62^{\mathrm{ns}}$ & $1,59^{\mathrm{ns}}$ \\
\hline DMS (5\%) & 192 & 2,03 & 0,41 & 0,82 & 3,42 \\
\hline $\mathrm{F} \times \mathrm{Fa}$ & $0,01^{\mathrm{ns}}$ & $1,98^{\mathrm{ns}}$ & $0,01^{\mathrm{ns}}$ & $2,27^{\mathrm{ns}}$ & $0,52^{\mathrm{ns}}$ \\
\hline CV $(\%)$ & 8,61 & 8,67 & 3,25 & 9,61 & 4,85 \\
\hline \multicolumn{6}{|c|}{ Doses de N $\left(\mathrm{kg} \mathrm{ha}^{-1}\right)(\mathrm{D})$} \\
\hline 0 & 1688 & 8,30 & 6,41 & 25,18 & 53,84 \\
\hline 60 & 2907 & 14,23 & 6,82 & 26,30 & 65,76 \\
\hline 120 & 3820 & 17,11 & 6,61 & 26,83 & 71,13 \\
\hline 180 & 3714 & 16,46 & 6,31 & 27,03 & 77,14 \\
\hline Teste F & $190,31^{* *}$ & $28,23^{* *}$ & $2,10^{\mathrm{ns}}$ & $7,33^{* *}$ & $60,64^{* *}$ \\
\hline F X D & $0,48^{\mathrm{ns}}$ & $2,03^{\mathrm{ns}}$ & $1,21^{\mathrm{ns}}$ & $0,78^{\mathrm{ns}}$ & $1,13^{\mathrm{ns}}$ \\
\hline $\mathrm{Fa} \times \mathrm{D}$ & $2,04^{\mathrm{ns}}$ & $0,54^{\mathrm{ns}}$ & $0,71^{\mathrm{ns}}$ & $1,96^{\mathrm{ns}}$ & $0,87^{\mathrm{ns}}$ \\
\hline CV $(\%)$ & 29,80 & 27,72 & 5,71 & 9,77 & 14,29 \\
\hline
\end{tabular}

${ }^{1}$ Médias seguidas de letras distintas, nas colunas, diferem entre si, pelo teste Tukey, a $5 \%$. ${ }^{2}$ Ureia contendo $0,045 \%$ de NBPT (n-butil tiofosfórico triamida). ${ }^{\text {ns }}$ Não significativo a $1 \%$ e $5 \%$.* Significativo a $1 \%$, pelo teste $\mathrm{F}$. 
condições, também foi observada por Carvalho et al. (2003), que avaliaram a resposta do feijoeiro à aplicação de doses de N, em plantio direto, e verificaram que a produtividade máxima seria alcançada com dose superior a $140 \mathrm{~kg} \mathrm{ha}^{-1}$. De fato, Soratto et al. (2004) relataram que, em sucessão à cultura do milho, a dose de $\mathrm{N}$ estimada para obtenção da máxima produtividade foi de $182 \mathrm{~kg} \mathrm{ha}^{-1}$.

A produtividade de grãos do feijoeiro correlacionou-se, significativamente, com o número de vagens por planta, massa de cem grãos e com a altura de plantas, o que demonstra que plantas mais robustas, e que produzem maior número de estruturas reprodutivas, são capazes de propiciar maiores produtividades, como também verificado por Soratto et al. (2006).

O número de vagens por planta foi influenciado pelas doses de nitrogênio, com efeito quadrático nas duas fontes e incrementos mais expressivos quando se aplicou $\mathrm{N}$ na forma de ureia aditivada
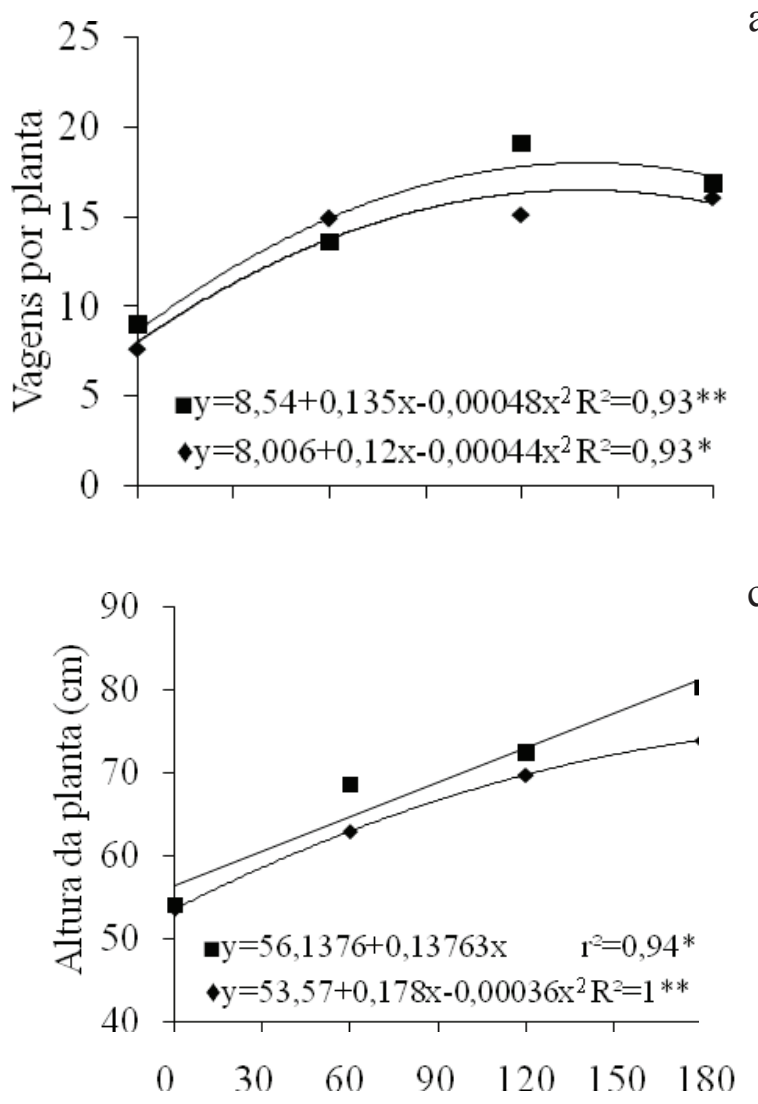

$\mathrm{a}$

c
(Figura 1a). Este resultado confirma a colocação de Portes (1996), de que esta característica sofre influência da adubação nitrogenada, já que, quando o feijoeiro apresenta deficiência de $\mathrm{N}$, ele produz menos flores e, consequentemente, menos vagens.

O número de grãos por vagem não apresentou diferenças significativas (Tabela 1), provavelmente por ser esta uma característica varietal pouco influenciada pela adubação (Andrade et al. 1998). Segundo Soratto et al. (2004), a aplicação de N em cobertura não causa grande variação no número de grãos por vagem. Isto é confirmado nos resultados obtidos por Silveira \& Damasceno (1993), Silva \& Silveira (2000) e por Crusciol et al. (2007).

Quanto à massa de cem grãos, esta foi influenciada pelas doses de $\mathrm{N}$ aplicado em cobertura (Tabela 1). A aplicação de doses maiores proporcionou a obtenção de grãos com maior massa, sendo o valor máximo obtido com aplicação de $175 \mathrm{~kg} \mathrm{ha}^{-1}$ de $\mathrm{N}$. As doses de ureia aditivada influenciaram, de forma
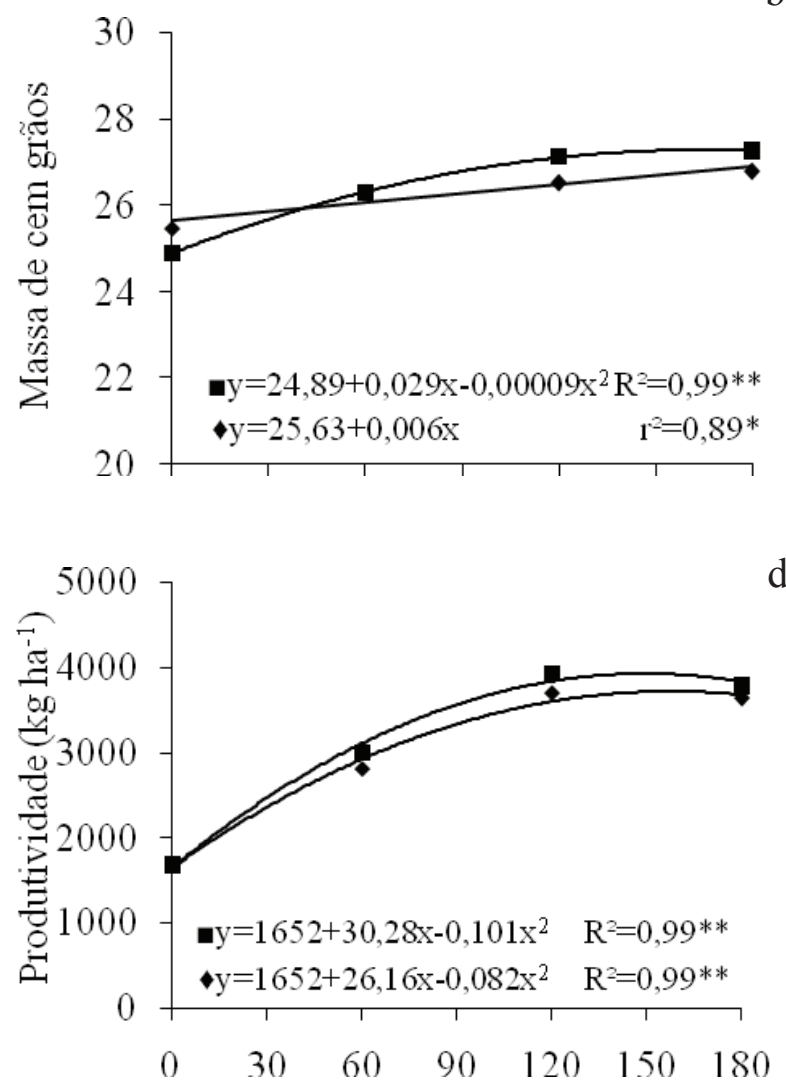

Nitrogênio em cobertura $\left(\mathrm{kg} \mathrm{ha}^{-1}\right)$

Figura 1. Número de vagens por planta (a), massa de cem grãos (b), altura da planta (c) e produtividade de grãos (d) do feijoeiro, em função de doses de nitrogênio aplicadas em cobertura, com ureia aditivada ( $\mathbf{\square})$ e ureia comum $(\star)$. $\mathrm{e}^{* *}$ : significativos a $5 \%$ e 1\%, pelo teste F, respectivamente (Santo Antônio de Goiás, GO, 2007). 
quadrática, a massa de cem grãos. Com as mesmas doses de N, tendo como fonte a ureia normal, foi observada resposta linear (Figura 1b). Estes resultados se assemelham aos de Soratto et al. (2006), que, com aplicação de doses de até $140 \mathrm{~kg} \mathrm{ha}^{-1}$ de $\mathrm{N}$ como ureia, em plantio direto, também observaram resposta linear, porém, discordam dos obtidos por Crusciol et al. (2007) e por Gomes Júnior et al. (2008), que avaliaram a resposta do feijoeiro cultivado em plantio direto, no mesmo tipo de solo, a doses de até $140 \mathrm{~kg} \mathrm{ha}^{-1}$ e $120 \mathrm{~kg} \mathrm{ha}^{-1}$, respectivamente, e não observaram influência sobre este componente.

A altura de plantas foi influenciada tanto pelas fontes quanto pelas doses de $\mathrm{N}$ (Tabela 1 e Figura 1c) e se correlacionou com a produtividade de grãos, assemelhando-se aos resultados de Soratto et al. (2006), que, também, obtiveram maiores produtividades relacionadas a plantas mais robustas. Este resultado é justificado pelo fato de que plantas maiores e com maior quantidade de ramificações são capazes de produzir maior número de estruturas reprodutivas (Portes 1996).

Verificou-se que, independentemente da fonte, a produtividade do feijoeiro ajustou a função quadrática às doses de $\mathrm{N}$ em cobertura (Figura 1d). Resposta diferenciada foi obtida por Crusciol et al. (2007), em que a dose máxima de $120 \mathrm{~kg} \mathrm{ha}^{-1}$ de $\mathrm{N}$ proporcionou aumento linear na produtividade, resultado que evidencia a maior exigência de $\mathrm{N}$ pelo feijoeiro, em plantio direto. No entanto, Soratto et al. (2006) trabalharam com doses de $\mathrm{N}$ de até $140 \mathrm{~kg} \mathrm{ha}^{-1}$ e também obtiveram resultados ajustados à função quadrática. Assim, no presente trabalho, o feijoeiro foi cultivado em sucessão a gramíneas, com base no fato de que, em resíduos culturais com elevada relação $\mathrm{C} / \mathrm{N}$ há maior imobilização de $\mathrm{N}$ para sua decomposição (Assis et al. 2003), sendo necessária maior quantidade deste nutriente para obtenção de produtividades satisfatórias.

Com a aplicação de ureia aditivada, a produtividade máxima (3.922 $\left.\mathrm{kg} \mathrm{ha}^{-1}\right)$ foi obtida com aplicação da dose estimada de $150 \mathrm{~kg} \mathrm{ha}^{-1}$ de $\mathrm{N}$ em cobertura, enquanto, para a ureia comum, a dose estimada foi de $160 \mathrm{~kg} \mathrm{ha}^{-1}$ de N, para obtenção da produtividade máxima $\left(3.738 \mathrm{~kg} \mathrm{ha}^{-1}\right)$. Assim, infere-se que a ureia aditivada confere maior eficiência à adubação nitrogenada. De fato, com a aplicação da ureia aditivada sobre a superfície, ou incorporada, observaram-se menores valores para o fator de utilização do $\mathrm{N}$ aplicado (Tabela 2).
Tabela 2. Aumento na produtividade de grãos do feijoeiro e fator de utilização do nitrogênio, considerando-se a aplicação da dose de $\mathrm{N}$ em cobertura, tendo como fonte ureia comum e aditivada (Santo Antônio de Goiás, GO, 2007).

\begin{tabular}{ccccc}
\hline \multirow{2}{*}{$\begin{array}{c}\text { Doses de N } \\
\left(\mathrm{kg} \mathrm{ha}^{-1}\right)\end{array}$} & \begin{tabular}{c} 
Ureia comum \\
\cline { 2 - 5 } \\
produtividade \\
$\left(\mathrm{kg} \mathrm{ha}^{-1}\right)^{(2)}$
\end{tabular} & $\begin{array}{c}\text { Fator } \\
\mathrm{N}^{(3)}\end{array}$ & $\begin{array}{c}\text { Aumento na } \\
\text { produtividade } \\
\left(\mathrm{kg} \mathrm{ha}^{-1}\right)\end{array}$ & $\begin{array}{c}\text { Fator } \\
\mathrm{N}\end{array}$ \\
\hline \multicolumn{5}{c}{ Superficial } \\
60 & 870 & 0,069 & 1121 & 0,053 \\
120 & 1851 & 0,065 & 2228 & 0,054 \\
180 & 1726 & 0,104 & 1941 & 0,093 \\
& \multicolumn{5}{c}{ Incorporada } \\
60 & 1386 & 0,043 & 1502 & 0,040 \\
120 & 2185 & 0,055 & 2266 & 0,053 \\
180 & 2178 & 0,083 & 2262 & 0,080 \\
\hline
\end{tabular}

Ureia contendo $0,045 \%$ do aditivo NBPT (n-butil tiofosfórico triamida).

${ }^{2}$ Calculado em relação à média de produtividade nas testemunhas, com ureia comum $\left(1690,70 \mathrm{~kg} \mathrm{ha}^{-1}\right.$ e $\left.1684,90 \mathrm{~kg} \mathrm{ha}^{-1}\right)$ e aditivada $\left(1624,10 \mathrm{~kg} \mathrm{ha}^{-1} \mathrm{e}\right.$ $\left.1751,10 \mathrm{~kg} \mathrm{ha}^{-1}\right)$, aplicadas sobre a superfície e incorporadas, respectivamente. ${ }^{3}$ Fator de utilização do $\mathrm{N}$ : quantidade de $\mathrm{N}\left(\mathrm{kg} \mathrm{ha}^{-1}\right) /$ aumento na produtividade, em relação à testemunha $\left(\mathrm{kg} \mathrm{ha}^{-1}\right)$.

$\mathrm{O}$ fator de utilização do $\mathrm{N}$ apresentado por Soratto et al. $(2004,2005)$ expressa a eficiência de determinada dose em aumentar a produtividade de grãos, em relação à testemunha. Assim, quanto maior $\mathrm{o}$ valor do fator $\mathrm{N}$, menor a eficiência na utilização do N, em determinada dose, fonte ou modo de aplicação, pois valores elevados indicam que o $\mathrm{N}$ aplicado não foi utilizado de forma eficiente, no sistema solo-planta, visto que não propiciou incrementos satisfatórios na produtividade da cultura. Verificou-se, desta forma, para as duas fontes, maior eficiência da adubação nitrogenada quando o fertilizante foi incorporado ao solo. A incorporação, por promover maior contato do fertilizante com o solo, propiciou maior aproveitamento do $\mathrm{N}$ aplicado.

\section{CONCLUSÕES}

1. No feijoeiro cultivado em plantio direto, sob integração lavoura-pecuária, o nitrogênio aplicado em cobertura, na forma de ureia comum ou aditivada, aumenta, de forma quadrática, a produtividade, até a dose estimada de $160 \mathrm{~kg} \mathrm{ha}^{-1}$ e $150 \mathrm{~kg} \mathrm{ha}^{-1}$ de N, respectivamente.

2. Na adubação em cobertura com ureia comum ou aditivada, a incorporação proporciona maior produtividade, em relação à aplicação superficial.

3. Em comparação com a ureia comum, a aplicação de ureia aditivada com NBPT em cobertura, no feijoeiro, não é capaz de promover aumentos significativos de produtividade. 


\section{REFERÊNCIAS}

AMADO, T. J. C.; MIELNIZUK, J.; FERNÁNDEZ, S. B. V. Leguminosas e adubação mineral como fontes de nitrogênio para o milho em sistemas de preparo do solo. Revista Brasileira de Ciência do Solo, Viçosa, v. 24, n. 1, p. 179-189, 2000.

ANDRADE, M. J. B. de et al. Resposta da cultura do feijoeiro à aplicação foliar de molibdênio e às adubações nitrogenadas de plantio e cobertura. Ciência e Agrotecnologia, Lavras, v. 22, n. 3, p. 499-508, 1998.

ASSIS, E. P. M. et al. Efeito da aplicação de nitrogênio na atividade microbiana e na decomposição da palhada de sorgo em solo de Cerrado sob plantio direto. Pesquisa Agropecuária Tropical, Goiânia, v. 33, n. 2, p. 107-112, 2003.

BARRETO, H. J.; WESTERMAN, R. L. Soil urease activity in winter wheat residue management systems. Soil Science Society of America Journal, Madison, v. 53, n. 10, p. 1455-1458, 1989.

BAYER, C.; MIELNICZUK, J. Características químicas do solo afetadas por métodos de preparo e sistemas de cultivo. Revista Brasileira de Ciência do Solo, Viçosa, v. 21, n. 1, p. 105-112, 1997.

CANTARELLA, H. et al. Fruit yield of Valencia sweet orange fertilized with different $\mathrm{N}$ sources and the loss of applied N. Nutrient Cycling in Agroecosystems, Dordrecht, v. 67 , n. 3, p. 205-213, 2003.

CARVALHO, M. A. C. et al. Doses e épocas de aplicação de nitrogênio e teores foliares deste nutriente e de clorofila em feijoeiro. Revista Brasileira de Ciência do Solo, Viçosa, v. 27, n. 3, p. 445-450, 2003.

CERETTA, C. A. et al. Nitrogen fertilizer split-application for corn in no-tillage succession to black oats. Scientia Agricola, Piracicaba, v. 59, n. 3, p. 549-554, 2002.

CONTIN, T. L. M. Ureia tratada com inibidor da uréase NBPT na adubação de cana-de-açúcar colhida sem despalha a fogo. 2007. 58 f. Dissertação (Mestrado em Agricultura Tropical e Subtropical)-Instituto Agronômico, Campinas, 2007.

COSTA, M. C. G.; VITTI, G. C.; CANTARELlA, H. Volatilização de $\mathrm{N}-\mathrm{NH}_{2}$ de fontes nitrogenadas em canade-açúcar colhida sem despalha a fogo. Revista Brasileira de Ciência do Solo, Viçosa, v. 27, n. 4, p. 631-637, 2003.

CRUSCIOL, C. A. C. et al. Fontes e doses de nitrogênio para o feijoeiro em sucessão a gramíneas no sistema plantio direto. Revista Brasileira de Ciência do Solo, Viçosa, v. 31, n. 6 , p. 1545-1552, 2007.

GOMES JÚNIOR, F. G. et al. Nitrogênio no feijoeiro em sistema de plantio direto sobre gramíneas. Acta Scientiarum Agronomy, Maringá, v. 30, n. 3, p. 387-395, 2008.

KLUTHCOUSKI, J.; STONE, L. F. Desempenho de culturas anuais sobre palhada de braquiária. In: KLUTHCOUSKI, J.; STONE, L. F.; AIDAR, H. (Eds.). Integração lavoura-pecuária. Santo Antônio de Goiás: Embrapa Arroz e Feijão, 2003. p. 499-522.
LARA CABEZAS, W. A. R. et al. Balanço da adubação nitrogenada sólida e fluida de cobertura na cultura de milho, em sistema plantio direto no Triângulo Mineiro (MG). Revista Brasileira de Ciência do Solo, Viçosa, v. 24, n. 2, p. 363-376, 2000.

MALHI, S. S. et al. Nitrogen fertilization management for no-till cereal production in the Canadian Great Plains: a review. Soil \& Tillage Research, Amsterdam, v. 60, n. 3, p. 101-122, 2001.

PORTES, T. A. Ecofisiologia. In: ARAÚJO, R. S. et al. (Coords.). Cultura do feijoeiro comum no Brasil. Piracicaba: Potafos, 1996. p. 101-137.

SANGOI, L. et al. Volatilização de N-NH em decorrência da forma de aplicação de ureia, manejo de resíduos e tipo de solo, em laboratório. Ciência Rural, Santa Maria, v. 33, n. 4 , p. $687-692,2003$

SCIVITTARO, W. B. et al. Uso do inibidor de uréase tiofosfato de $N$-n-butiltriamida em cultivo de arroz irrigado. Pelotas: Embrapa Clima Temperado, 2008.

SILVA, C. C. da; SILVEIRA, P. M. da. Influência de sistemas agrícolas na resposta do feijoeiro (Phaseolus vulgaris L.) irrigado à adubação nitrogenada em cobertura. Pesquisa Agropecuária Tropical, Goiânia, v. 30, n. 1, p. 86-96, 2000.

SILVEIRA, P. M. da. et al. Adubação nitrogenada no feijoeiro cultivado sob plantio direto em sucessão de culturas. Pesquisa Agropecuária Brasileira, Brasília, DF, v. 40, n. 4, p. 377-381, 2005.

SILVEIRA, P. M. da.; DAMASCENO, M. A. Doses e parcelamento de $\mathrm{K}$ e de $\mathrm{N}$, na cultura do feijoeiro irrigado. Pesquisa Agropecuária Brasileira, Brasília, DF, v. 28, n. 11, p. 1269-1276, 1993.

SILVEIRA, P. M. da.; STONE, L. F. Manejo da irrigação do feijoeiro: uso do tensiômetro e avaliação do desempenho do pivô central. Santo Antônio de Goiás: Embrapa Arroz e Feijão, 1994

SORATTO, R. P.; CARVALHO, M. A. C. de; ARF, O. Nitrogênio em cobertura no feijoeiro cultivado em plantio direto. Revista Brasileira de Ciência do Solo, Viçosa, v. 30, n. 2, p. 259-265, 2006.

SORATTO, R. P.; CARVALHO, M. A. C. de; ARF, O. Teor de clorofila e produtividade do feijoeiro em razão da adubação nitrogenada. Pesquisa Agropecuária Brasileira, Brasília, DF, v. 39, n. 9, p. 895-901, 2004.

SORATTO, R. P. et al. Aplicação tardia de nitrogênio no feijoeiro em sistema de plantio direto. Bragantia, Campinas, v. 64, n. 2, p. 211-218, 2005.

WATSON, C. J. Urease activity and inhibition: principles and practice. London: The International Fertilizer Society, 2000

WATSON, C. J. et al. Soil properties and the ability of the urease inhibitor N-(n-butyl) thiophosporic triamide (NBPT) to reduce ammonia volatilization from surfaceapplied urea. Soil Biology \& Biochemistry, Oxford, v. 26, n. 9 , p. $1165-1171,1994$. 